\title{
Численное моделирование процесса самоочистки в многомодовом волокне с градиентным профилем показателя преломления при распространении волны накачки и стоксовой компоненты
}

\author{
$\underline{\text { О.С. Сидельников }}^{1, *}$, Е.В. Подивилов ${ }^{1,2}$, С.А. Бабин ${ }^{1,2}$, М.П. Федорук ${ }^{1,3}$ \\ ${ }^{I}$ Новосибирский государственный университет \\ ${ }^{2}$ Институт автоматики и электрометрии СО РАН \\ ${ }^{3}$ Институт вычислительных технологий СО РАН \\ *E-mail: o.sidelnikov@g.nsu.ru
}

DOI: 10.31868/RFL2020.110-111

Пространственно-временная динамика светового пучка в многомодовых волокнах в настоящее время вновь вызывает интерес как с точки зрения фундаментальной физики, так и в различных областях практического применения [1,2]. Недавние эксперименты в этой области [2,3] показали, что благодаря нелинейному эффекту Керра в многомодовых волокнах с градиентным профилем показателя преломления может наблюдаться процесс самоочистки пучка. В данной работе мы с помощью численного моделирования исследуем процесс самоочистки при одновременном распространении стоксовой волны и волны накачки в многомодовом волокне с параболическим профилем показателя преломления.

Рассматривалось градиентное многомодовое волокно диаметром 100 мкм и длиной 1 км с показателем преломления сердцевины $\mathrm{n}_{\mathrm{co}}=1.47$ и $\Delta=8.8 \cdot 10^{-3}$. По волокну одновременно распространялись две волны - накачка мощностью 150 ВТ на длине волны $\lambda_{\mathrm{P}}=940$ нм и стоксовая компонента мощностью 5 Вт на длине волны $\lambda_{\mathrm{S}}=980$ нм. На вход подавалась волна накачки, имеющая параболической профиль, заполняющий всю сердцевину волокна. Для стоксовой компоненты использовался гауссов пучок, близкий к фундаментальной моде.

Первым рассматривался случай моделирования процесса распространения стоксовой волны и волны накачки с помощью балансных уравнений:

$$
\begin{gathered}
\frac{d I_{S}}{d z}=q_{R} I_{P} I_{S}, \\
\frac{d I_{P}}{d z}=-q_{R} \frac{\lambda_{S}}{\lambda_{P}} I_{S} I_{P},
\end{gathered}
$$

где $I_{P}$ и $I_{S}$ - интенсивность накачки и стоксовой компоненты, $q_{R}=g_{R} \cdot S_{P}^{e f f}$, $g_{R}=0.1$ дБ/(Вт·км) и $S_{P}^{e f f}$ - эффективная площадь накачки. На Рис. 1 (а) представлено входное и выходное распределение для волны накачки и стоксовой компоненты (см. вставку), полученное с помощью балансных уравнений. Как мы можем видеть, волна накачки истощается в центре, и в профиле распределения образуется большое углубление. Это происходит за счет того, что стоксовая компонента имеет небольшой радиус, и в рамках данной модели обмен энергии осуществляется только между точками, имеющими одинаковые пространственные координаты.

Однако балансные уравнения не позволяют описывать эффекты, связанные с дисперсией, нелинейностью и случайной связью пространственных мод. Поэтому в данной работе для численного исследования процесса распространения волны накачки и стоксовой компоненты нами была также рассмотрена система уравнений, основанная на модели связанных мод: 


$$
\begin{aligned}
\frac{\partial A_{p, m}}{\partial z} & =\sum_{m 1, p 1} C_{m, p}^{m 1, p 1} A_{m 1, p 1}- \\
& -i k_{S} \frac{n_{2}}{n_{c o}} \sum_{m 1, m 2, m 3} \sum_{p 1, p 2, p 3} f_{p 1, p 2, p 3, p}^{m 1, m 2, m 3, m}\left(A_{p 1, m 1}^{*} A_{p 2, m 2}+(2+i f) B_{p 1, m 1}^{*} B_{p 2, m 2}\right) A_{p 3, m 3}, \\
\frac{\partial B_{p, m}}{\partial z} & =\sum_{m 1, p 1} C_{m, p}^{m 1, p 1} B_{m 1, p 1}- \\
& -i k_{P} \frac{n_{2}}{n_{c o}} \sum_{m 1, m 2, m 3} \sum_{p 1, p 2, p 3} f_{p 1, p 2, p 3, p}^{m 1, m 2, m 3, m}\left(B_{p 1, m 1}^{*} B_{p 2, m 2}+(2+i f) A_{p 1, m 1}^{*} A_{p 2, m 2}\right) B_{p 3, m 3} .
\end{aligned}
$$

Здесь $A_{p, m}$ и $B_{p, m}$ - амплитуды модовых компонент стоксовой волны и волны накачки соответственно, $f$ - отношение между рамановской и керровской константами и коэффициенты $C_{m, p}^{m 1, p 1}$ соответствуют случайной линейной связи пространственных мод. В качестве начальных данных для такой модели в случае стоксовой компоненты использовалось разложение гауссова пучка соответствующего радиуса на пространственные моды. Для волны накачки все моды изначально имели равные интенсивности и случайные фазы. После усреднения по различным реализациям случайных фаз полученное распределение накачки было близко к параболическому профилю.
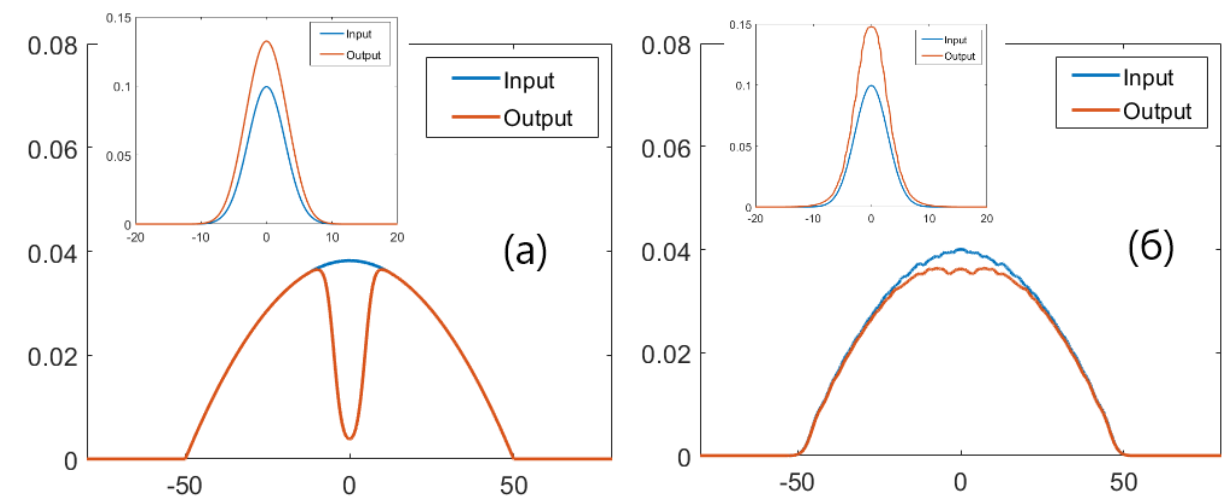

Рис. 1. Входное и выходное распределение для волны накачки, полученное с помощью модели балансных уравнений (а) и модели связанных мод (б).

На Рис. 1 (б) представлено входное и выходное распределение для волны накачки и стоксовой компоненты, полученное с помощью модели связанных мод. Как мы можем видеть, в данном случае за счет случайной линейной связи мод и керровской нелинейности при распространении происходит перетекание энергии в фундаментальную моду накачки, и в профиле распределение возникает лишь небольшое углубление.

Работа Федорука М.П. (теоретический анализ) была выполнена при поддержке проекта РНФ № 20-11-20040. Работа Сидельникова О.С. (математическое моделирование) была поддержана государственным заданием на проведение фундаментальных исследований № FSUS-2020-0034.

\section{Литература}

[1] Y. Wakayama, D. Soma et al, J. Lightwave Technology 37, 404-410 (2019)

[2] K. Krupa, A. Tonello et al, Nat. Photon. 11, 234 (2017)

[3] E.V. Podivilov, D.S. Kharenko et al, Phys. Rev. Lett. 122, 103902 (2019) 